\title{
The Research Review of Intelligent Tourism
}

\author{
Hong Jiang \\ ${ }^{1}$ Management School, Shanghai University of Engineering and Science, Shanghai, China \\ Correspondence: Hong Jiang, Number 56, Lane 800, Wenhui Road, Songjiang University Town, Songjiang District, \\ Shanghai, China. Tel: 86-188-1823-5989. E-mail: 15035755616@163.com \\ Received: October 9, 2013 \\ Accepted: October 29, 2013 \\ Online Published: November 9, 2013 \\ doi:10.5430/jms.v4n4p65 \\ URL: http://dx.doi.org/10.5430/jms.v4n4p65
}

\begin{abstract}
Tourism industry is comprehensive, so it is able to converge with a great deal of industries. A case in point is intelligent tourism. Recently with the informatization increasingly developing, intelligent tourism has been taken seriously by the government and its fast development requires theories to support. Based on documentation methods, this paper classified the intelligent tourism theories by referring to and studying all the relevant theories. So the paper introduced the research themes about intelligent tourism: the definition of the concept, the building and the influence of intelligent tourism. At last, the thesis reviewed relevant papers on the research methods, contents and tendency.
\end{abstract}

Keywords: intelligent tourism, documentation methods, literature review

\section{Introduction}

Intelligent tourism stems from "Intelligent Earth and Intelligent City". The concept of intelligent tourism was put forward in the report of "Towards a low carbon travel and tourism industry" in May,2009.Then,Zhenjiang city of Jiangsu province in China put forward the concept of intelligent tourism initiatively and creatively and developed related project in 2010. In addition, the director of China National Tourism Administration formally announced that China is going to implement "intelligent tourism" in 10 years. Also, the government established the first batch of pilot cities of intelligent tourism, such as Ningbo and Nanjing in China. Intelligent tourism is so fresh that the relevant papers were so deficient. The paper introduces the concept definition, the development, and the influence of intelligent tourism according to collect and summarize the related literatures. At last, the paper reviews the study method, content and trend.

\section{Introduction of Related Literature}

\subsection{Definition of Intelligent Tourism}

\subsubsection{Concept Review of Intelligent Tourism}

Intelligent tourism is new neoterm and until now there is not a unitive concept, which has a bad effect on the development of intelligent tourism and tourism science.

According to the related papers, the author draws these conclusions: these concepts are almost tourists-centric and indicate the basic point, which is to meet tourists' needs. What's more, they manifest intelligent tourism is the means not the final goal. However, there is something deficient, which does not understand "intelligence" and "tourism". For example, they view intelligence as information (Xie, Jie, 2012, 96-98) and cannot differentiate intelligence and digit (Yao, Gu, 2012; Deng, X.F., \& Li, X., 2012; Zhang, L.Y., Li, N., \& Liu, M., 2012). And not concern all factors of tourism system.

\subsubsection{The Basic Concepts of Intelligent Tourism}

The author considered that intelligent tourism denotes the technologies such as internet of things, cloud computing, internet, intelligent data mining and so on are applied to tourism industry, which integrates and activities the tourism physical and informational resources to improve tourism service, improve the tourism experience, innovate tourism management and enhance tourism enterprises competitiveness.

\subsection{The Development of Intelligent Tourism}

This kind of papers constituting a reasonable proportion of all papers can be classified to three types: first is the study of national development, and second is about provinces and cities and the third is upon tourism enterprises. 


\subsubsection{National Development of Intelligent Tourism}

These papers mainly introduce the countermeasure study about intelligent tourism in China and the development of tourism informationize about public service. Jin, Jiangjun (2012) indicated three aspects of countermeasures: stressing the application of new information technology, setting up database of tourism resources and advance service level of tourism information in (Jin, J.J., 2012, 22-23). The paper did not reflect the establishment from the perspective of tourism system. Ding, Fengqin (2012) undertook to build intelligent tourism from tourism basic facility, tourism resources integration, intelligent industries which are related to tourism industry and community participation (Ding, Fengqin, 2012). This paper gets advanced than the other papers before. Because it considered the other related industries and benefit of community member.

\subsubsection{Regional Development of Intelligent Tourism}

This kind of papers were development strategies about cities such as Jiangsu, Zhejiang, Shandong and Shanxi Provinces and Xinjiang autonomous region of China, which made the study more objective. Yan Min (2012) put forward targeted suggestions to develop intelligent tourism in Nanjing, China; such as the construction of database and application system, informatization management, the service level and efficiency and strengthening the pilots and so on (Yan Min, 2012, 76-77). Ji Hui (2012) visualized ideas and key of development of intelligent tourism in Shandong, China. The paper presented related solutions aimed at four main application groups: tourism administration, tourist attractions hotels and travel agency (Ji Hui, 2012, 73-78).

\subsubsection{Tourism Corporation Development of Intelligent Tourism}

Tourism contains food, accommodation, transportation, traveling, shopping, entertainment. And intelligent tourism adds tourism to the six parts. So the scholars analyse tourism corporations to make the researches more specific and operational. The majority of the papers are the researches of intelligent tourist attractions, while the intelligent hotels are deficient. The scholars' study is mainly based on theories and application technologies. Shao Zhenfeng (2010) initiated to release papers about intelligent tourists attractions. The author presented management structural diagram upon intelligent tourists attractions basing on internet of things (Shao, Z.F., Zhang, X.P., Ma, J., et al, 2010). Moreover, Shao Zhenfeng elaborated how to manage and construct smart tourist attractions (Deng, G.P., Shao, Z.F., 2011). Zu Qi (2011) denoted safety management with pattern recognition (Zuo, Q., Ai, C.Y., Tang, J., 2011). As for the theory researches, Ge Junlian (2012) took the benefits of stakeholders seriously to avoid the benefit was owned by tourist attractions only. Therefore, it can contribute to the multiple stakeholders and even the local tourism development (Ge, J.L., Gu, X.J., \& Long, Y., 2012)

The papers about intelligent hotels are quite deficient. Zhao, Huanyan (2012) introduced the characteristics and value. So in the future, we should study more about theoretical framework and the evaluation standard system of intelligent and even the development strategies (Liu, J.L., \& Fan, Y.F., 2011, 121-124).

\subsection{Impact of Intelligent Tourism}

The impact of tourism is always the key point of many tourism scholars. It is well known that tourism industry possesses huge economic, social and ecological effect. The influence of intelligent tourism can promoted tourism to upgrade rapidly and will bring the second evolution of tourism industry and have a impact on other industries.

Ding, Fengqin (2012) presented the impact and significant of intelligent tourism: to satisfied more boarder and deep demands to foster the change of tourism management style, the development of new industry and the establishment of intelligent cities. The author mainly researched the promotional value of intelligent tourism and underlined that the development of intelligent tourism can promote the change of tourism industrial patten. Wan, Xiaoqing (2012) indicated that we should introduce the intelligent tourism system into the publicity and education effectively to meet visitors' needs and perform museum duties about spread knowledge (Wan, Xiaoqin, 2012, 78-79). The paper mainly stated the function and application of intelligent tourism system, which is the innovation of concept and method. Liu Junmei (2012) indicated that intelligent tourism have great influence on industrial transformation and put forward the countermeasures of industrial transformation about Xinjiang autonomous region of China(Liu, X.X., Yan, M., \& Zhang, J.F., et al, 2012, 93-95).

Tourists are the important participators in tourism activities. Therefore, the study focused on tourists which are always the key point, which contains the motive, demand, behaviors, decision, satisfaction degree and so on. Intelligent tourism, which is seen as the important way to promote quality of tourists' experience, must have impact on them. However, the relevant papers are quite few. Wang, Jun (2012) denoted that the tourists' behaviors get more autonomous and individual as the fact that tourists can obtain diverse and general information in the age of intelligent tourism (Wang, J., Liu, S.N., 2012). The tourists are not just limited to traditional tourism mode and pay much attention to the individual experience in the process of tour. Comparatively speaking, intelligent tourism has greater impact on young persons. 


\section{Review of Intelligent Tourism Research}

In conclusion, the research about intelligent tourism referred to the definition of intelligent tourism, the development of intelligent tourism and impact of intelligent tourism. Although in recent years, intelligent tourism research has become more and more, but these papers were not so profound and specific.

1). As to the research methods, the methods about intelligent tourism in recent study were consulting literature materials, experts consultation and case analysis. And there were not quantitative method to analyse intelligent tourism. So, we should enrich the research methods and strengthen the combination of theoretical analysis and empirical analysis. What's more, we should use the related theories and methods to advance the research of intelligent tourism, such as information economics, marketing, psychology and sociology and so on.

2). As for the research content, since these papers remained exploratory stage, the theoretical researches stressed on the study in the macro level and had not study profoundly and intensively. As to the concept definition, the scholars have not reached the agreement. Most definition was descriptive, and just was the collection of its pattern of manifestation and could not embody the essence and connotation of intelligence and tourism. About the development of intelligent tourism, these papers presented some projects and suggestions, which owned some practical meaning, but they were lack of logic and the practical significance was deficient.

3). As for the research trend, with the information industry upgrading and developing and the government attached great importance on the intelligent city and the intelligent tourism,the research trend must be more extensive and profound. In recent literatures, we could find that the research area was expending from macro building framework to the development of city and tourism corporations and even to the study of tourists' behavior and decision. So the researches about the intelligent tourism will pay much attention to the practical application and apply the smart information technology to the tourists attractions to solve problems and provide some advice.

\section{References}

Deng, G.P., \& Shao, Z.F. (2011). Intelligent Scenic Spots Management Based on Video Cruise of Jiuzhaigou. Computer Engineering and Design, 11, 3920-3924.

Deng, X.F., \& Li, X. (2012). Evaluation Standard System Research of Intelligent Tourists Attractions. E-Government, 9, 100-105.

Ding, Fengqin. (2012). Countermeasures Research of Intelligent Tourism and Countermeasures. China Urban Economy, 1, 32-34.

Ge, J.L., Gu, X.J., \& Long, Y. (2012). The Development Research of Intelligent Tourists attractions Based on Stakeholders Theory. Productivity Research, 5, 183-184.

Ji, Hui. (2012). Research of Intelligent Tourism in Shandong. Journal of Internet of Things, 12, 73-78.

Jin, J.J. (2012). Development Countermeasures Research of Intelligent Tourism. China Information Times, 11, 22-23.

Liu, J.L., \& Fan Y.F. (2011). The Form, Value and Development Trend of Intelligent Tourism. Chongqing Social Sciences, 10, 121-124.

Liu, X.X., Yan, M., Zhang, J.F., \& et al. (2012). The Research on Transformation and Upgrading strategies of Tourism Industry in Xinjiang. Market Forum, 11, 93-95.

Shao, Z.F., Zhang, X.P., Ma J., \& et al. (2010). Intelligent Scenic Spots Management Based on Internet of Things of Jiuzhaigou. Geomatics World, 5, 12-16.

Wan, Xiaoqin. (2012). The Application of Intelligent Tourism System to Education and Publicity in Museum. Computer Compact disc Software and Application, 18, 78-79.

Wang, J., \& Liu, S.N. (2012). Tourists Consumption Behavior Research in the Age of Intelligent Tourism. Guide of Science and Technology, 32, 60-159.

Xie, Jie. (2012). The Construction of Intelligent Tourism. Information System Engineering, 6, 96-98.

Yan, Min. (2012). Intelligent Tourism and its development----A Case of Nanjing,Jiangsu Province. Tourism Management, 76-77.

Yao, Gu. (2012). A study on the construction framework of intelligent tourism. Journal of Nanjing University of Posts and Telecommunications, 14(2), 14.

Zhang, L.Y., Li, N., \& Liu, M. (2012). On the Basic Concept of Smarter Tourism and Its Theoretical System. Tourism Tribune, 27(5), 66.

Zuo, Q., Ai, C.Y., \& Tang, J. (2011). Intelligent Tourists attractions Security System Based on Pattern Recognition of Qin Chengshan--Du Jiangyan. Chinese Garden, 9, 33-35. 